\title{
The effects of an interplanetary shock on the high-latitude ionospheric convection during an IMF $B_{y}$-dominated period
}

\author{
I. Coco ${ }^{1}$, E. Amata ${ }^{1}$, M. F. Marcucci ${ }^{1}$, D. Ambrosino ${ }^{1}$, J.-P. Villain ${ }^{2, \dagger}$, and C. Hanuise ${ }^{2}$ \\ ${ }^{1}$ Istituto di Fisica dello Spazio Interplanetario (IFSI), INAF, Rome, Italy \\ ${ }^{2}$ Laboratoire de Physique et Chimie de l'Environnement (LPCE), CNRS/Université d'Orléans, Orléans, France \\ $\dagger$ deceased January 2008
}

Received: 4 April 2008 - Revised: 25 July 2008 - Accepted: 27 August 2008 - Published: 25 September 2008

\begin{abstract}
On 6 January 1998 an interplanetary shock hit the magnetosphere around 14:15 UT and caused a reconfiguration of the northern high-latitude ionospheric convection. We use SuperDARN, spacecraft and ground magnetometer data to study such reconfiguration. We find that the shock front was tilted towards the morning flank of the magnetosphere, while the Interplanetary Magnetic Field (IMF) was $B_{y}$-dominated, with $B_{y}<0$, IMF $B_{z}>0$ and $\left|B_{y}\right| \gg B_{z}$. As expected, the magnetospheric compression started at the first impact point of the shock on the magnetopause causing an increase of the Chapman-Ferraro current from dawn to dusk and yielding an increase of the geomagnetic field at the geostationary orbit and on the ground. Moreover, the high-latitude magnetometer data show vortical structures clearly related to the interaction of the shock with the magnetosphere-ionosphere system. In this context, the SuperDARN convection maps show that at very high latitudes above the northern Cusp and in the morning sector, intense sunward convection fluxes appear, well correlated in time with the SI arrival, having a signature typical for $B_{z}>0$ dominated lobe reconnection. We suggest that in this case the dynamic pressure increase associated to the shock plays a role in favouring the setting up of a new lobe merging line albeit $\left|B_{y}\right| \gg B_{z} \geq 0$.
\end{abstract}

Keywords. Interplanetary physics (Interplanetary shocks) Magnetospheric physics (Magnetosphere-ionosphere interactions; Plasma convection)

\section{Introduction}

The global patterns of the high-latitude ionospheric convection are mostly determined by magnetic reconnection at the magnetopause and in the tail. When the Interplanetary Mag-

Correspondence to: I. Coco

(igino.coco@ifsi-roma.inaf.it) netic Field (IMF) points southward, i.e. when its GSM $z$ component is negative $\left(B_{z}<0\right)$, reconnection occurs close to the subsolar magnetopause and far in the tail, producing a two-cell ionospheric convection pattern where plasma flows antisunward in the polar cap, and sunward at lower latitudes; when $B_{z}>0$, reconnection should take place at high latitudes tailward of the Cusps, producing double reversed-cell patterns, where plasma flows sunward in the polar cap and antisunward at lower latitudes (e.g. Dungey, 1961; Burke et al., 1979; Huang et al., 2000). The IMF $B_{y}$ component acts on the size and the symmetry of the convection patterns in the east-west direction: when $B_{y}<0(>0)$ the whole pattern is rotated dawnward (duskward) and the dusk (dawn) cell is usually bigger than the other one (e.g. Crooker, 1979; Reiff and Burch, 1985; Gosling et al., 1990; Ruohoniemi and Greenwald, 1996, 2005). When $B_{z} \geq 0$, an important role can be played by the magnetic dipole tilt and the IMF $B_{x}$ component (Cowley, 1983; Crooker and Rich, 1993; Lockwood and Moen, 1999): the dipole tilt could favour reconnection tailward of the Cusp in the Northern Hemisphere during the boreal summer, and in the Southern Hemisphere during the austral summer; however, a large negative (positive) $B_{x}$ is believed to alter such seasonal effect, and favour reconnection tailward of the Northern (Southern) Cusp.

The variations of solar wind dynamic pressure are known to affect the energy and momentum transfer between the solar wind and the magnetosphere and, as a consequence, the ionospheric convection patterns (e.g. Sibeck, 1990; Araki, 1994). To this respect, two important factors are the rise time and the duration of the pressure perturbation. For short rise times strong transient perturbations are observed both in the magnetosphere and in the ionosphere until a new location of the magnetopause boundary is established; on the other hand, the duration of a pressure perturbation determines whether the effects will be localized or global (Boudouridis et al., 2003).

Published by Copernicus Publications on behalf of the European Geosciences Union. 
If the duration is long enough to engulf most of the magnetosphere in the solar wind region of enhanced/reduced pressure, the pressure variation causes typical global increases of the geomagnetic field strength measured at the geostationary orbit, and on the ground at equatorial and middle latitudes, which are usually called Sudden Commencements (SC) or Sudden Impulses (SI), depending on whether they are followed by a geomagnetic storm (SC), or not (SI); in such cases, often one refers to the pressure variation itself as an SI, and this is the notation we will follow from now on. A pressure perturbation of that kind generates a compressive MHD wave which will propagate in the magnetospheric cavity (e.g. Wilken et al., 1982; Southwood and Kivelson, 1990; Erlandson et al., 1991). Coupling to the high-latitude ionosphere requires the generation of a Field Aligned Current (FAC) system that is carried by a field-guided Alfvén mode: this can occur where inhomogeneities exist in the magnetospheric plasma and magnetic field (Araki, 1994, and references therein). The FAC system leads to the formation of pairs of current and convection vortices in the highlatitude ionosphere, almost symmetric around noon, whose signatures are well identified in ground magnetometers (e.g. Araki, 1994; Russell and Ginskey, 1995), and radar data (e.g. Thorolfsson et al., 2001; Vontrat-Reberac et al., 2002): they cover wide magnetic latitude and local time regions and their centres usually lie on closed field lines. Also aurora observations have evidenced SI-induced global effects: the brightness of the aurora and the intensity of electron precipitation increase in the whole oval, and a southward expansion of the equatorward edge of the auroral oval has often been reported (e.g. Zhou and Tsurutani, 1999; Boudouridis et al., 2003; Kozlovsky et al., 2005). It is generally thought that FieldLine Resonances (FLRs) can originate in the inner magnetosphere due to the Alfvén modes excitation, and this mechanism, along with the pure mechanical compression caused by the SI, can transfer enough energy to the trapped particles to cause them to escape the confinement via the loss-cone instability. Ground traces of FLRs or, in general, of periodic field oscillations (Pc5) have been actually observed, closely related to solar wind pressure perturbations (e.g. Prikryl et al., 1998; Francia et al., 1999; Motoba et al., 2003). As these effects are thought to take place on closed field lines, one does not expect to observe relevant ground SI signatures at very high latitudes, where the footprints of the Cusps and of the Low Latitude Boundary Layer (LLBL) usually map. Nevertheless, Newell and Meng (1994) have found through the statistical observation of the precipitating particles, that the ionospheric Cusps and the LLBL are considerably larger during periods of high solar wind dynamic pressure than when the pressure is low, and Coco et al. (2005) also observed that the number of SuperDARN radar echoes increases both at latitudes in the oval and at higher latitudes in the Cusp during an SI.

Pressure pulses of shorter time scales, on the other hand, are not supposed to lead to a global reconfiguration of the magnetosphere, but rather to induce local bulges or indentations in the magnetopause, which propagate along that boundary, dragged by the solar wind motion. Many models exist to explain the coupling with the high-latitude ionosphere (e.g. Glassmeier et al., 1989; Kivelson and Southwood, 1991; Sibeck et al., 2003). Without going too deeply in the details, there is a general agreement on the fact that FACs are generated inside the magnetosphere where the plasma density gradient suffers a steep change, e.g. at the boundary between the LLBL and the Central Plasma Sheet. FACs map in the ionosphere at latitudes close to the Open-Closed field line Boundary (OCB) leading one or more vortex-like structures, that move following the footprints of the FACs. Such vortices are also called Travelling Convection Vortices (TCV), and a recent review on that topic can be found in Zesta et al. (2002).

In this paper we study an event during which a large dynamic pressure increase (SI) occurred in the solar wind in coincidence with a strong IMF $B_{y}$ decrease and try to identify and describe the effects induced on the ionospheric convection by the SI on one hand and by the IMF change on the other. The study is mainly based on SuperDARN Northern Hemisphere convection maps, but makes also use of ground magnetometer data and of space borne data. The paper is structured as follows: Sect. 2 offers an overview of the observations made by spacecraft in the solar wind and in the magnetosphere (Sect. 2.1), by ground-based magnetometers (Sect. 2.2), and by SuperDARN in the Northern Hemisphere (Sect. 2.3); the observations are then discussed in detail in Sect. 3 and Sect. 4 contains a brief summary of our conclusions.

\section{Observations overview}

\subsection{Observations in space}

Figure 1 shows, from top to bottom: the solar wind dynamic pressure observed by WIND on 6 January 1998 between 13:15:38 and 13:45:38 UT ( $3 \mathrm{~s}$ resolution, GSM position: $\left.X=227 R_{E}, Y=20 R_{E}, Z=-5 R_{E}\right)$; the GSM $B_{x}, B_{y}, B_{z}$ components of the IMF as observed by IMP-8 on 6 January 1998 between 14:00 and 14:30 UT ( $16 \mathrm{~s}$ resolution, GSM position: $\left.X=29 R_{E}, Y=-1 R_{E}, Z=14.5 R_{E}\right)$; the GSM $B_{z}$ component of the magnetic field as observed by GEOTAIL on 6 January 1998 between 14 and 14:30 UT (3 s resolution, GSM position: $X=7 R_{E}, Y=6 R_{E}, Z=0.5 R_{E}$ ). In the figure, the WIND data have been delayed by $44^{\prime} 22^{\prime \prime}$ in order to match the IMP-8 and GEOTAIL features. At 13:28:57 UT (14:12:09 UT in the top panel of Fig. 1), a sharp discontinuity of the plasma parameters is observed at WIND (red dashdotted line): the pressure jumps from 2 to $6 \mathrm{nPa}$, due to increases of both the proton number density $\left(\Delta n \simeq 12 \mathrm{pp} / \mathrm{cm}^{3}\right)$ and velocity $(\Delta V \simeq 80 \mathrm{~km} / \mathrm{s})$. As the increase of the solar wind velocity exceeds the Alfvén and sound speeds of the 


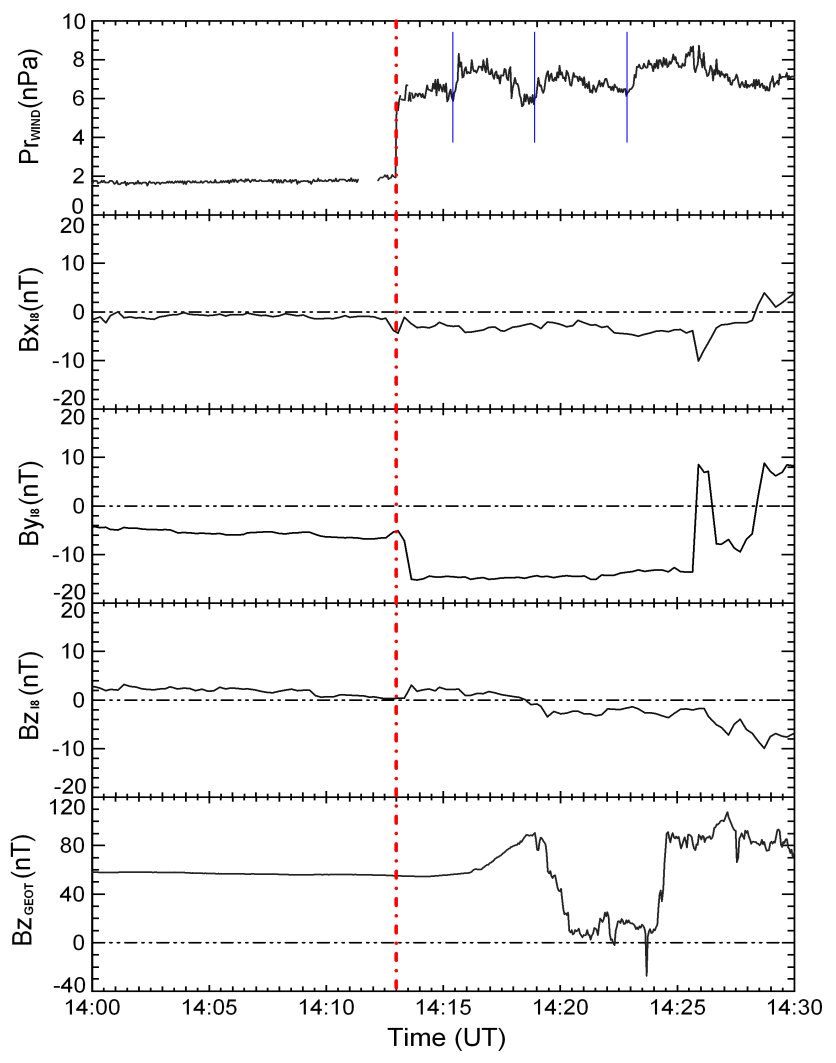

Fig. 1. WIND, IMP-8 and GEOTAIL observations on 6 January 1998. From top to bottom: solar wind dynamic pressure (in $\mathrm{nPa}$ ) measured by WIND, IMF $B_{x}, B_{y}, B_{z}$ GSM components (in nT) measured by IMP-8, and the GSM $B_{z}$ component of the magnetic field measured by GEOTAIL. The UT time refers to IMP- 8 and GEOTAIL observations, while WIND observations are delayed by $44^{\prime} 22^{\prime \prime}$.

undisturbed solar wind $\left(V_{A} \simeq 31 \mathrm{~km} / \mathrm{s}\right.$ and $C_{s} \simeq 38 \mathrm{~km} / \mathrm{s}$, respectively), the discontinuity is an interplanetary shock. After the shock, at least three minor pressure variations are seen, of the order of 1.5-2 nPa, each one lasting for about 4 5 min (blue lines in the figure). At IMP-8 a clear discontinuity is observed in the IMF data at 14:13:20 UT, when a steep decrease of the $B_{y}$ component occurs from -7 to $-15 \mathrm{nT}$. Before the discontinuity $B_{z}$ is positive (fourth panel from the top), or just close to zero; when the discontinuity occurs, $B_{z}$ has a small increase and switches to negative values at about $14: 18$ UT. $B_{x}$ is slightly negative or close to zero during the whole interval (second panel from the top). Unfortunately, no plasma data are available for IMP-8 at this time, but we can unambiguously identify this IMF feature as the shock observed at WIND at 13:28:57 UT, thanks to the fact that the main IMF features observed at IMP-8 are also observed at WIND and at ACE (which was at about $20 R_{E}$ from WIND). In order not to overload the figure, we displayed IMF data for IMP-8 only, which is located much closer to the Earth's bow shock and magnetopause than WIND and ACE. At GEO-

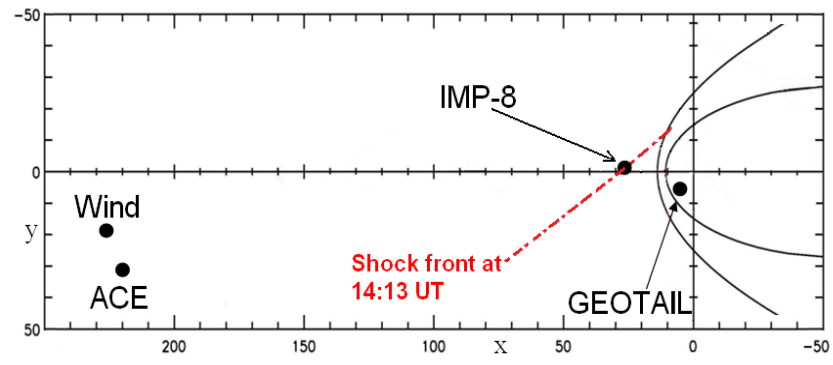

Fig. 2. Locations of the spacecraft used in this study in the $X Y$ GSM plane (axis scales in Earth radii, $R_{E}$ ).

TAIL all the field components experience a progressive increase starting around 14:16 UT (only $B_{z}$ is shown, as an example, in Fig. 1, bottom panel), indicating that the interplanetary shock has reached the magnetopause and the magnetosphere is being compressed, until the field components switch over about $80 \mathrm{~s}$, starting at 14:19 UT, to values typical of the magnetosheath, indicating that the magnetopause has been pushed past the GEOTAIL position.

The time delay between the WIND and the IMP-8 observations of the bow shock is $\Delta t=44^{\prime} 22^{\prime \prime}$, i.e. it is substantially shorter than the ballistic travel time between the two spacecraft along the $X$ axis: $\Delta t \simeq \Delta X / V \simeq 55^{\prime} 30^{\prime \prime}$ (as $\Delta X=198 R_{E}$ and the solar wind speed behind the shock is $380 \mathrm{~km} / \mathrm{s}$ ). This suggests that the shock front is probably tilted so that its normal forms an angle greater than $180^{\circ}$ with the GSM $X$ axis, as we will further discuss in Sect. 3.1. Figure 2 shows the average locations of the bow shock and the magnetopause and the positions, projected onto the $X Y$ GSM plane, for all satellites whose data have been inspected for the present study. Figure 2 also displays the intersection with the GSM $X Y$ plane at IMP-8 of a tilted shock front compatible with the observed delays.

\subsection{Ground-based magnetometer observations}

Figure 3 shows the horizontal component $(X)$ of the geomagnetic field for a selection of four low latitude magnetometers with $1 \mathrm{~min}$ resolution, displayed in increasing order of Magnetic Local Time (MLT) from top to bottom, on 6 January 1998 between 14:00 and 14:30 UT. All four magnetograms show an increase starting at 14:16:30 UT, i.e. 3 min after the passage of the shock at IMP-8, and lasting until 14:22 UT, with a signature very similar to that observed by GEOTAIL. The effect appears to be global and simultaneous, and has the characteristics of an SI. Nevertheless, the $X$ component variation is generally small, not exceeding 40-50 nT, with the only exception of Huancayo, located near the geomagnetic equator on the morning side, where the SI amplitude reaches 120 nT.

Figure 4 shows $5 \mathrm{~s}$ sampling magnetograms of the $X$ (North-South) component of the geomagnetic field (left hand panels) and of the $Y$ (East-West) component (right hand 


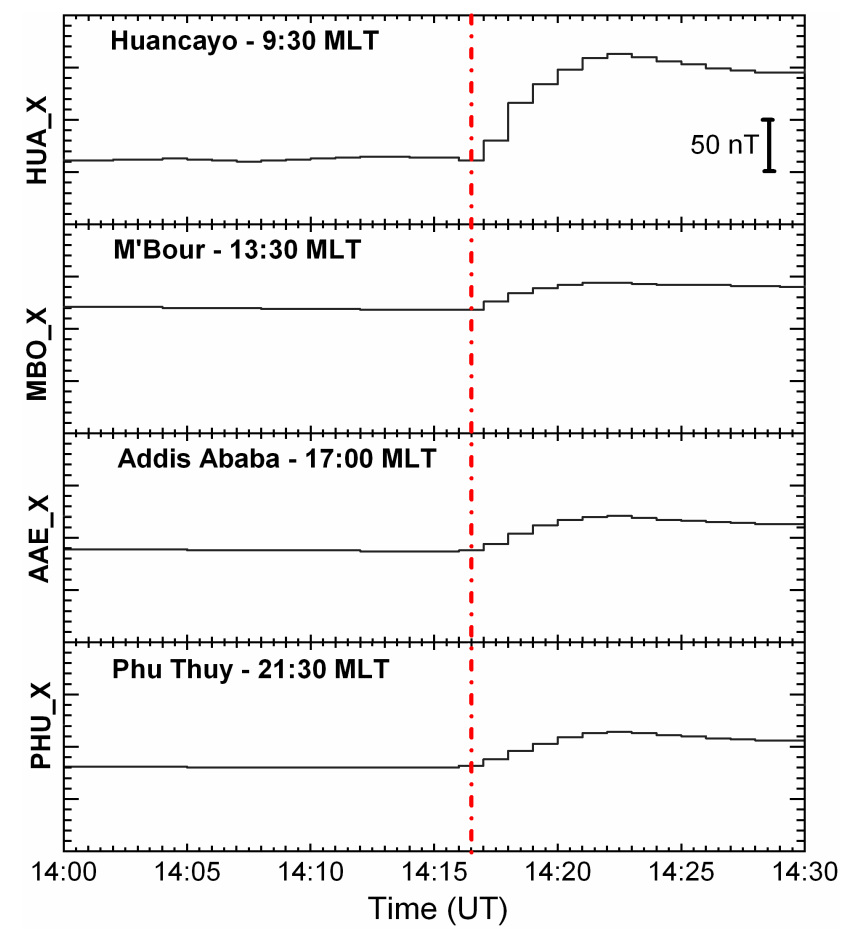

Fig. 3. Horizontal component $(X)$ of magnetograms from groundbased stations close to the geomagnetic equator, in increasing order of MLT from top to bottom, on 6 January 1998 between 14:00 and 14:30 UT.

panels) between 13:45 and 14:45 UT on 6 January 1998 for four stations belonging to the Magnetometer Array for Cusp and Cleft Studies (MACCS), while no data could be retrieved for this period from the Canopus magnetometer chain. The stations are all located between $\sim 07: 00$ and $\sim$ 10:00 MLT and are presented, from top to bottom, in decreasing order of Magnetic Latitude (MLAT). The $X$ component of the higher latitude stations (RES, $\sim 83^{\circ}$ MLAT, and PEB, $\left.\sim 79^{\circ} \mathrm{MLAT}\right)$ is not affected much by the interplanetary shock: only a broad wave-like disturbance is noticed, starting at 14:15:40 UT at RES and at 14:16:30 UT at PEB and lasting several minutes, with peak-to-peak amplitude not exceeding $40 \mathrm{nT}$. On the other hand, at lower latitude stations (CHB and $\mathrm{CDR} \sim 75^{\circ} \mathrm{MLAT}$ ), the $X$ component shows signatures which can be related to the shock: at 14:15:40 UT a double pulse starts, with a short and steep negative peak at 14:16 UT, which precedes a broader and smoother positive peak at 14:18:20 UT. Looking at the $Y$ component (right side of Fig. 4) of the magnetograms, both lower and higher latitude stations show a dip of the field starting between 14:15:30 and 14:17 UT and lasting for about ten minutes.

After the SI signature, both the $X$ and the $Y$ components at lower latitude stations show a series of magnetic transients (see the red dashed lines in Fig. 4) which have the following characteristics: 1) The $X$ and the $Y$ components show a phase difference of about $90^{\circ}, 2$ ) the transients are first noticed at
CDR ( 09:40 MLT), then at CHB ( 09:00 MLT), i.e. they move westward, away from noon; the estimated speed is 7$8 \mathrm{~km} / \mathrm{s}$.

Figure 5 shows a selection of $20 \mathrm{~s}$ sampling magnetograms from four stations between 13:00 and 15:00 MLT, which belong to the Danish Meteorological Institute (DMI) array and to the Magnetometer Array on the Greenland Ice Cap (MAGIC), in decreasing order of MLAT, from top to bottom, on 6 January 1998 between 13:45 and 14:45 UT. The $H$ (North-South) and the $E$ (East-West) components of the geomagnetic field are displayed in the left and right hand panels, respectively. In general, the $H$ component starts to decrease at 14:15:40 UT, although the rate is different from station to station. As a matter of fact one can recognize a different behaviour between the higher and lower latitude stations. At the two higher latitude stations (MCG, 76.4 ${ }^{\circ} \mathrm{MLAT}$, and DNB, $\sim 75.2^{\circ}$ MLAT) we observe a broader response of the $H$ component, which slowly decreases until about 14:18 UT, while the $E$ component does not display strong variations until 14:17 UT, when a rapid fall occurs at both stations, not exceeding $40 \mathrm{nT}$. The lower latitude stations (GHB, $\sim 70.5^{\circ}$ MLAT, and AMK, $69.3^{\circ}$ MLAT) show a bipolar pulse of both the $H$ and $E$ components: a fast pulse with negative slope precedes a broader pulse with positive slope. That signature starts at about 14:15:40 UT and lasts for about 8 min.

In conclusion, we can say that the first effects of the shock passage at the high-latitude dayside ground magnetometers show up roughly $3 \mathrm{~min}$ after its detection by IMP-8.

\subsection{SuperDARN convection maps}

The Super Dual Auroral Radar Network (SuperDARN) is fully described by Greenwald et al. (1995) and by Chisham et al. (2007). The Doppler phase-shift of the radar echoes allows to determine the velocities of the sounded ionospheric irregularities along the line of sight. As in the $\mathrm{F}$ region such irregularities follow the drift of the ambient plasma, this yields a measure of the plasma convection velocity (e.g. Hanuise et al., 1985; Villain et al., 1986). In the common mode of operation, a complete scan of the whole field of view is performed in two minutes over 16 azimuthal beams and 75 range gates with a typical space resolution of $45 \mathrm{~km}$. In addition to the line of sight velocity, from each beam and range the analysis of the radar echoes allows to calculate the signal-to-noise ratio (maximum reflected power) and the spectral width. This last quantity is related to the plasma turbulence processes in the sounded region, and is often used to discriminate the ionospheric footprints of different magnetospheric regions (e.g. Hanuise et al., 1993; Baker et al., 1995; Chisham et al., 2008).

In order to have a global picture of the high-latitude ionospheric convection, it is often useful to merge the line-ofsight velocities measured by the single SuperDARN radars through the map potential technique (Ruohoniemi and Baker, 

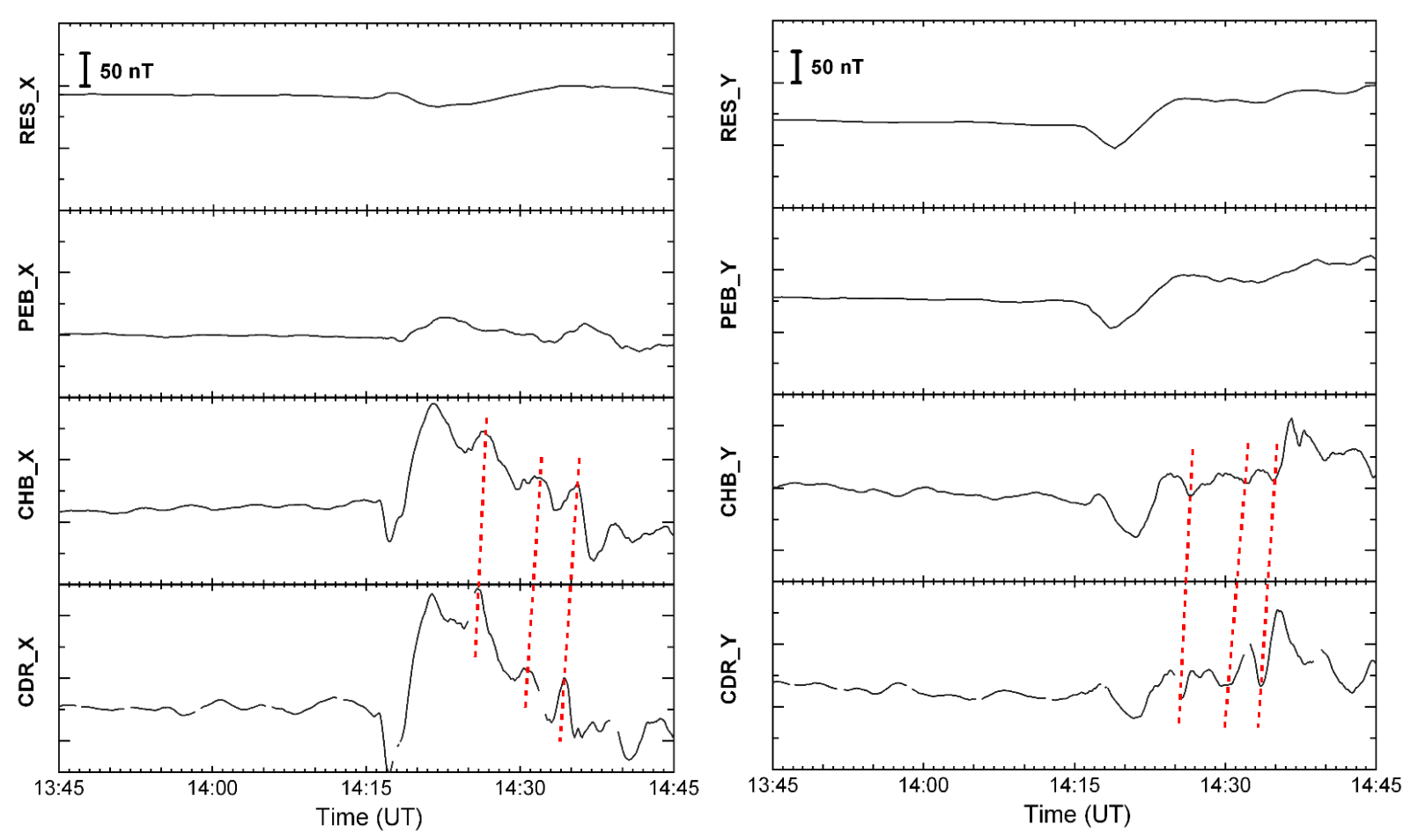

Fig. 4. High latitude magnetograms from the MACCS chain, above Northern Canada (morning MLT), on 6 January 1998 between 13:45 and 14:45 UT. The left side of the figure shows the $X$ (North-South) component, the right side displays the $Y$ component (East-West). The stations are displayed in decreasing order of magnetic latitude from the northernmost, on top (RES - Resolute Bay, $\sim 83^{\circ}$ MLAT), to the southernmost, on bottom (CDR - Cape Dorset, $\sim 74.5^{\circ} \mathrm{MLAT}$ ). The red dashed lines evidence the evolution of magnetic transients moving from CDR to CHB.

1998). The efficiency of the technique in recostructing the actual convection streamlines crucially depends on data coverage: the technique makes use of additional data points determined by an empirical model of convection (Ruohoniemi and Greenwald, 1996 and 2005); where the coverage is good, the reconstructed maps are univocally determined by the actual measurements while, conversely, in cases of poor or absent coverage, the influence of the model on the convection patterns is very strong. For the present event, we carefully inspected the original velocities measured along the fields of view for all the available radars, and verified that all the features described hereafter are consistent with the actual radar measurements.

The results of the map potential analysis can be seen in Figs. 6 which display two 2-min potential maps each, from 14:14 to 14:30 UT. In each panel positive (negative) potential contours are drawn by solid (dashed) curves and represent also flow streamlines. Velocity vectors obtained through the map potential technique are drawn as pointers at the locations where actual SuperDARN measurements are available. The strength of the vectors is colour coded according to the scale on the left of each panel. The IMF observations taken as reference are those of IMP-8, delayed by $3 \mathrm{~min}$, that we have evaluated in Sect. 2.2 to be the time necessary for the shock effects to start in the ionosphere. The inset in the top right of each panel shows the orientation of such an IMF in the $Y Z$ GSM plane. The positions of the high-latitude magnetometers mentioned in the previous section are also displayed in all panels.

- Fig. 6, panel (a): 14:14 $\rightarrow$ 14:16 UT. Before the shock arrival the IMF $B_{z}$ is close to zero and only slightly positive, while $B_{y}<0$, as shown by the top right inset. As one would expect in this situation, the high-latitude ionospheric convection as observed by SuperDARN is rather weak and consists of an asymmetric two-cell pattern (which we mark by $\alpha$ and $\beta$ in this panel) confined above $70^{\circ}$ MLAT. The dawn cell extends slightly across the noon MLT meridian so that the convection velocity is directed from dawn to dusk around noon; on the other hand, the dusk cell exhibits a sort of tongue extending towards dawn at lower latitudes. This situation persisted for several 2 min scans before and is well represented by the scan displayed in this panel.

- Fig. 6, panel (b): 14:16 $\rightarrow$ 14:18 UT. This panel shows the convection immediately after the passage of the shock front which was accompanied by a large increase of the absolute value of IMF $B_{y}<0$ (see again the top right inset). The two-cell pattern has clearly evolved towards a more complicated one. Actually, the convection 
pattern has not changed noticeably on the dusk side (see the $\beta^{\prime}$ cell), while, on the contrary, on the morning side very clear sunward fluxes appear above $75^{\circ}$ MLAT between 06:00 and 10:30 MLT, which the map potential software interprets as separating a counterclockwise cell extending along the noon MLT meridian (marked with a $\gamma^{\prime}$ ) from a small clockwise cell with focus at 07:30 MLT and $74^{\circ}$ MLAT. The reconstruction of such sunward fluxes is based on data from three radars (Kapuskasing, Goose Bay and Stokkseyri), whose fields of view overlap over the area of interest.

- Fig. 6, panel (c): 14:18 $\rightarrow$ 14:20 UT. The sunward fluxes in the morning persist. A reverse (counterclockwise) convection cell around noon is now completely formed $\left(\gamma^{\prime}\right)$, and the map potential software again suggests the existence of another reverse cell in the morning $\left(\delta^{\prime}\right)$.

- Fig. 6, panel (d): 14:20 $\rightarrow$ 14:22 UT. The $\gamma^{\prime}$-cell can be still recognised, but it extends now more duskward, and an increase of convection fluxes from noon to dusk is reported above central Greenland. In the morning the convection has suffered strong variations with respect to the previous scan: between 10:00 MLT and noon and around $77^{\circ}-78^{\circ}$ MLAT westward and equatorward fluxes emerge, which resemble the northernmost part of a counterclockwise vortex, while between 08:00 and 10:00 MLT, eastward and equatorward fluxes survive, perhaps the remainings of the $\delta^{\prime}$-cell shown in panels (b) and (c).

- Fig. 6, panel (e): 14:22 $\rightarrow$ 14:24 UT. The reverse cell in the polar cap has disappeared, and a clockwise convection cell is being restored in the afternoon. In the morning, westward fluxes are still present between 10:00 MLT and noon, while a reconfiguration seems to occur between 06:00 and 10:00 MLT, where a counterclockwise convection cell is developing. These changes occur at a time when the time shifted IMP-8 IMF $B_{z}$ has just turned negative.

- Fig. 6, panel (f): 14:28 $\rightarrow$ 14:30 UT. After some minutes during which the high-latitude ionosphere adjusts to the modified IMF conditions $(14: 24 \rightarrow 14: 26$ and $14: 26 \rightarrow 14: 28$ UT scans, not shown), the final configuration of the convection is given by a two-cell pattern, with the dusk side cell protruding towards the morning, as expected for the given IMF orientation.

\section{Discussion}

\subsection{Shock front orientation and time delays}

First of all, we discuss the timing of the arrival at the ionosphere of the first effects of the SI. As we have shown in
Sect. 2.2, the equatorial ground magnetograms (Fig. 3) display an increase of the $H$-component starting at 14:15:20 UT, while in the magnetosphere a similar increase is observed in the $B_{z}$ GSM component measured by GEOTAIL. These are the effects of the interplanetary shock hitting the magnetopause: the compression launches a fast magnetosonic wave which propagates in the equatorial magnetosphere and eventually causes an increase of the North-South component of the ground geomagnetic field. The field rise time is about 4-5 min at all stations, which is very close to the values observed for shocks nearly perpendicular to the $X$ GSM direction (e.g. Wang et al., 2006). However, as we have noted in Sect. 2.2, the compression of $H$ is not homogeneous, being the field increase stronger in the morning sector at Huancayo station at $\sim 09: 30$ MLT. This fact suggests that the shock first stroke the magnetopause at the morning side, in agreement with the considerations made in Sect. 2.1 regarding the shock propagation from WIND to IMP-8. On this line, a possible orientation of the shock front compatible with the observed delay of 3 min between the IMP-8 SI detection and the first effects at the equatorial and high-latitude ionosphere (see Sect. 2.2) was drawn as a red line through the IMP-8 position in Fig. 2. Unfortunately a quantitative estimate of the shock front orientation and of the shock speed close to $1 \mathrm{AU}$ is not possible because of the lack of IMP-8 plasma data at that time. However, we could make a qualitative estimate of that orientation by using IMF and plasma WIND data: by applying the Coplanarity Theorem (e.g. Schwartz, 1998) we obtained $\hat{\boldsymbol{n}} \simeq(-0.88,0.45,-0.2)$, which forms an angle $\varphi \simeq 208^{\circ}$ with the $X$ axis in the GSM $X Y$ plane. Such a tilt agrees with the shock hitting first the magnetopause morning side, although it does not fully match the shock orientation drawn in Fig. 2.

\subsection{Araki-type and TCV-like effects}

On the basis of a comprehensive study of high-latitude magnetometer signatures, Araki (1994) inferred that, during a symmetric magnetospheric compression (i.e. a pressure discontinuity whose normal is aligned with the Sun-Earth direction), two current systems are established at high latitudes: first, a pair of FACs comes with the magnetosonic front motion, one directed downward into the auroral zones in the afternoon, and the other directed upward out from the ionosphere in the morning; the closure currents in the highlatitude ionosphere form vortical structures, clockwise in the afternoon, counterclockwise in the morning; a magnetometer located northward of the centre of a clockwise (counterclockwise) current vortex will experience an increase (decrease) of the North-South component, an eastward (westward) Hall current being established in the ionosphere. The opposite signature will be observed by a station located southward of the vortex centre. This current system is called Preliminary Impulse (PI). When the shock front is passing along the magnetopause flanks, the compressed magnetosphere tends 

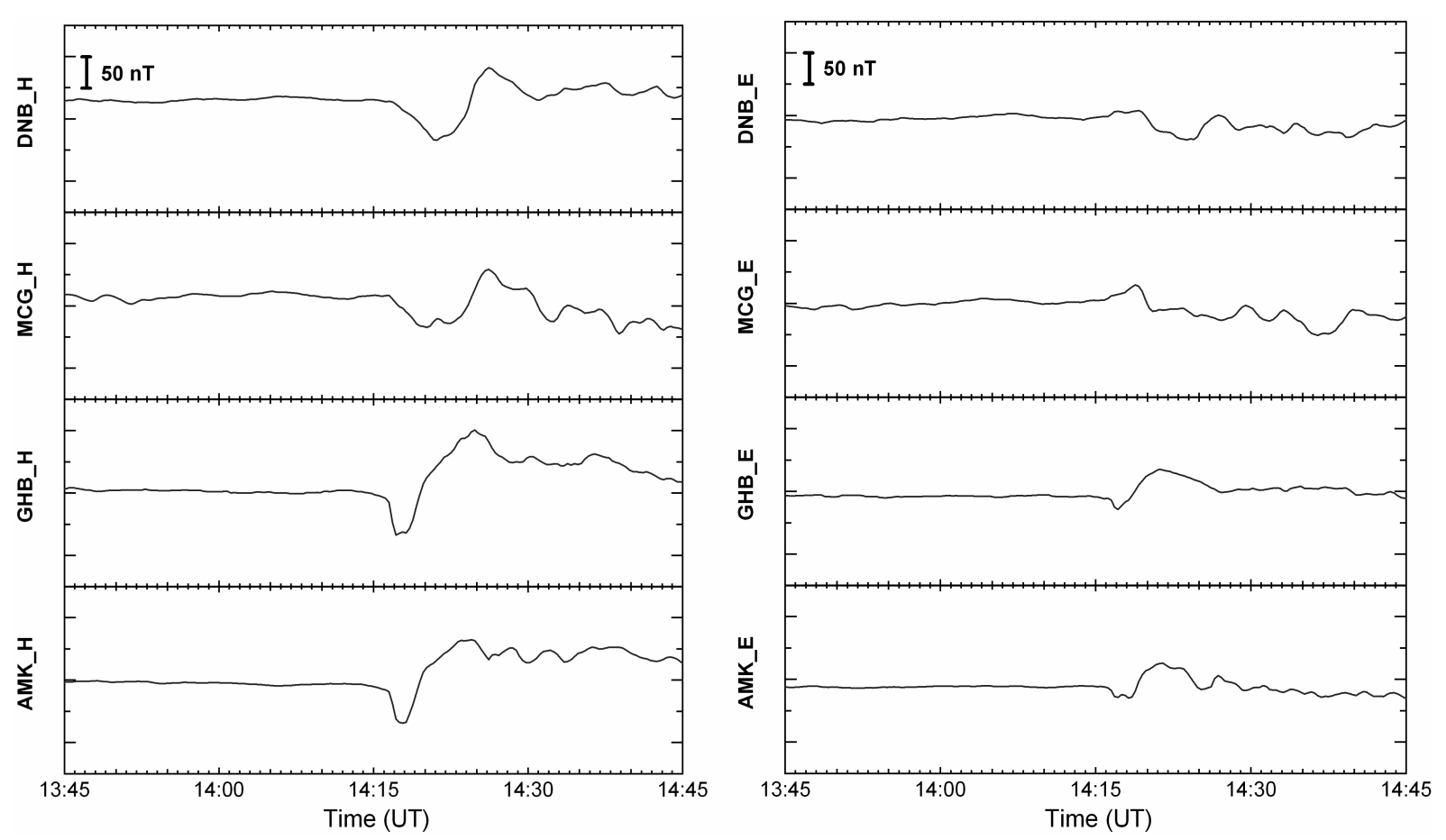

Fig. 5. High latitude magnetograms from the DMI and MAGIC Greenland chains (afternoon MLT), on 6 January 1998 between 13:45 and 14:45 UT. On the left side the North-South component $(H)$ is shown, while on the right side one can see the East-West component $(E)$. The stations are displayed in decreasing order of magnetic latitude from the northernmost, on top (MCG - MAGIC-1 GISP , 76.4 ${ }^{\circ}$ MLAT), to the southernmost, on bottom (AMK - Ammassalik, $\sim 69.3^{\circ}$ MLAT).

towards a new equilibrium, with the increase of the dawndusk electric field; this causes an inversion of the FACs system, that now appears as a pair of filamentary currents entering the auroral zones in the morning and flowing out in the afternoon; in such way, all vortices and magnetometer signatures are reversed (Main Impulse, MI). In summary, the resulting magnetic signatures at high latitudes consist of bipolar PI/MI structures with the PI having a steeper slope and a shorter duration than the MI and with opposite sign in the dawn and dusk sectors.

For the event under study, the proposed orientation of the shock front could result in an asymmetry of the Araki vortex systems with respect to the 12:00 MLT meridian, possibly to such an extent that both systems develop in the morning side. To this regard, we have shown in Sect. 2.2 that the CDR, CHB, GHB and AMK magnetograms do show features of the PI/MI kind (see Figs. 4 and 5), which clearly appear to be related to the SI, but display the same polarities both in the morning sector (CDR and CHB) and in the afternoon sector (GHB and AMK), i.e. a decrease followed by an increase of the North-South component. The available data do not allow to determine unambiguously the topology of the FAC system which is responsible for such observations. However, they can be reconciled with the Araki model by assuming that $\mathrm{CDR}$ and $\mathrm{CHB}$, which are located at $\simeq 75^{\circ}$ MLAT, observe the northern part of a current vortex which starts counterclockwise and turns into clockwise, while AMK and GHB, which are located slightly above $70^{\circ}$ MLAT, observe the southern part of a current system which starts clockwise and turns into counterclockwise. If that is so, the AMK GHB vortices are located in the early afternoon, while the CDR - CHB vortices are located around 09:00 MLT. This asymmetry with respect with the 12:00 MLT meridian to some extent qualitatively agrees with the probable orientation of the shock front.

As we do not have other magnetometer data to further support this interpretation, we can try to make use of the SuperDARN observations, which provide convection velocities in the $\mathrm{F}$ region (while from the magnetometers we can reconstruct the orientation of E region currents). For this event, the SuperDARN coverage is satisfactory only above $75^{\circ}$ MLAT and, moreover, the time resolution of the network $(2 \mathrm{~min})$ is too low to identify the details of the evolution of the PI vortices. However, we notice from Fig. $6 \mathrm{~d}$ and e that the northernmost part of a counterclockwise convection vortex can be seen in the morning, between $76^{\circ}$ and $78^{\circ}$ MLAT, and 09:00 and 11:00 MLT, slightly northward of CDR. A comparison with Fig. 4 can be made: between 14:20 and 14:24 UT, i.e. the interval encompassing the two scans of Fig. $6 \mathrm{~d}$ and e, CDR and CHB are observing a peak of the $X$ component; these are the final moments of life of the MI current system in the morning, when a clockwise current vortex reaches its 


\section{(a) 14:14 - 14:16 UT}

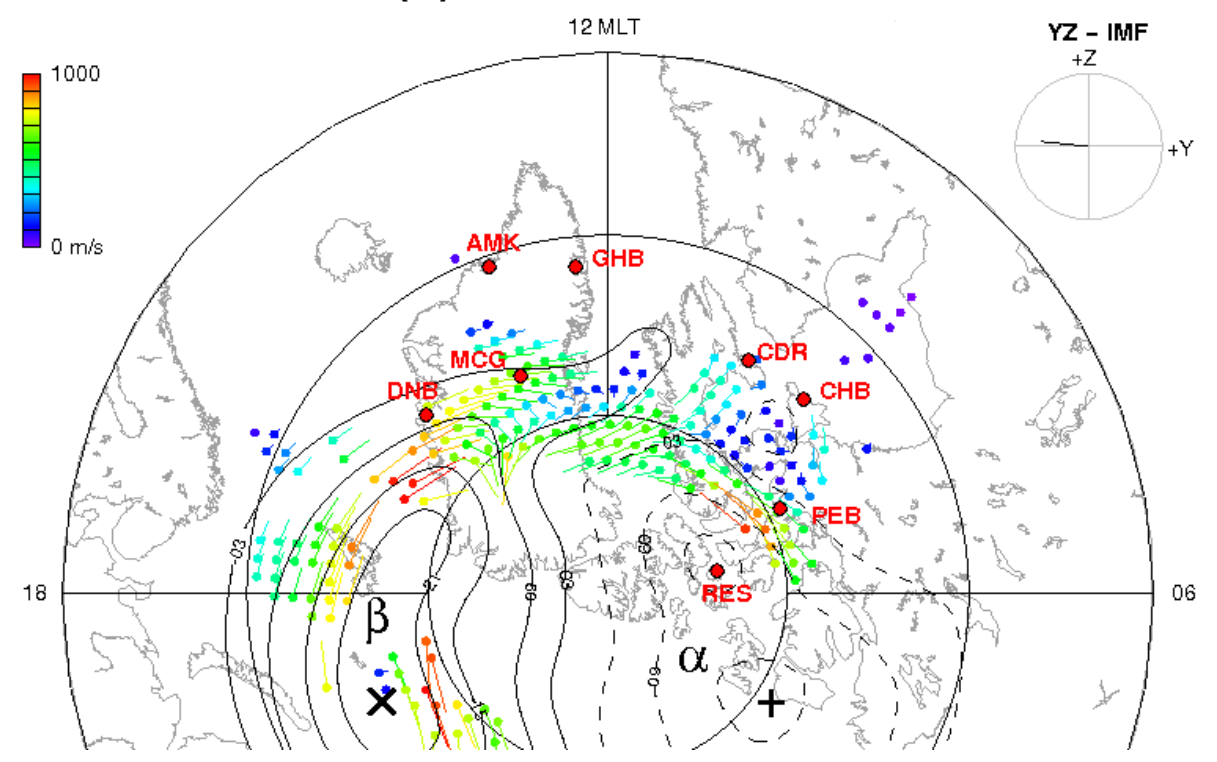

(b) 14:16 - 14:18 UT

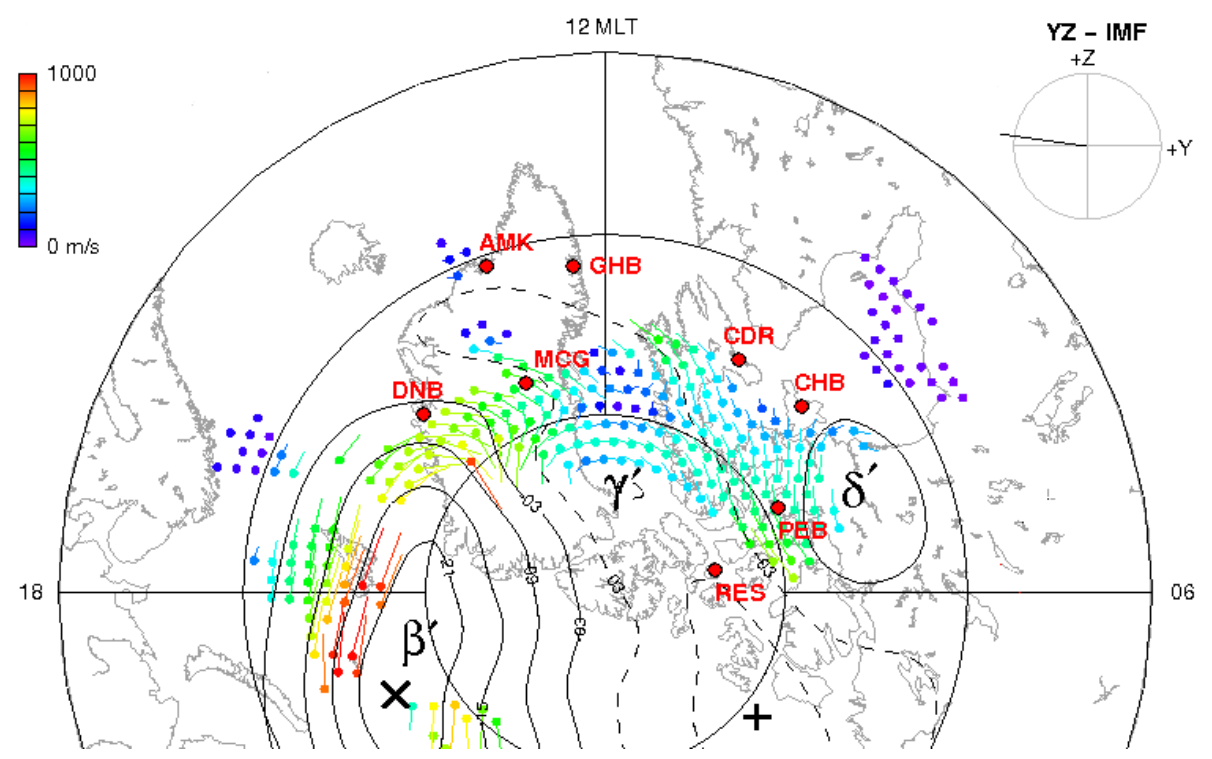

Fig. 6. Northern Hemisphere SuperDARN convection maps for 6 January 1998, between 14:14 and 14:20 UT. Each map corresponds to a 2 min complete SuperDARN scan. Convection velocities follow the color scale shown on the top left. On the top right of each panel, an inset displays the IMF orientation in the $Y Z$ GSM plane, averaged over the scan time. The locations of magnetometers whose data have been described in Sect. 2.2 are also shown.

maximum intensity and then begins to fade. As SuperDARN measures the $\boldsymbol{E} \times \boldsymbol{B}$ plasma convection velocity, a counterclockwise convection vortex corresponds to a clockwise current vortex, so that magnetometers and radars observations seem to agree. In the afternoon, the high-latitude convection measurements made by SuperDARN fall rather far in MLAT from the AMK and GHB stations by at least $5^{\circ}$ to allow a comparison similar to the one we just made for the morning side. However, between 14:18 and 14:22 UT, ve- locities pointing towards dusk along the local MLAT parallel around $75^{\circ}$ MLAT between 12:00 and 14:00 MLT are observed which do not contradict the existence of a clockwise Araki MI vortex at lower MLATs.

To complete the discussion of the effects induced by the solar wind dynamic pressure in the magnetogram records, we recall that in the solar wind, after the main pressure increase, at least three minor pressure variations occurred (see Fig. 1). As Fig. 4 shows and as we described in Sect. 2.2, 


\section{(c) 14:18 - 14:20 UT}

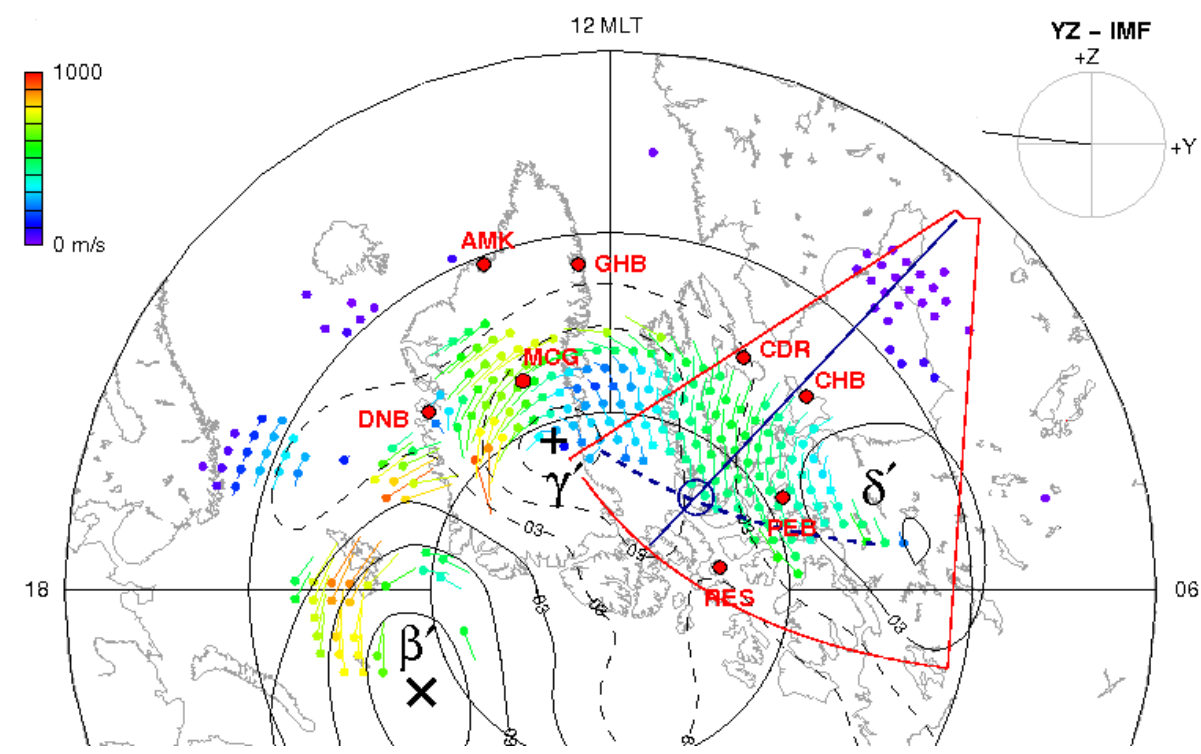

(d) 14:20 - 14:22 UT

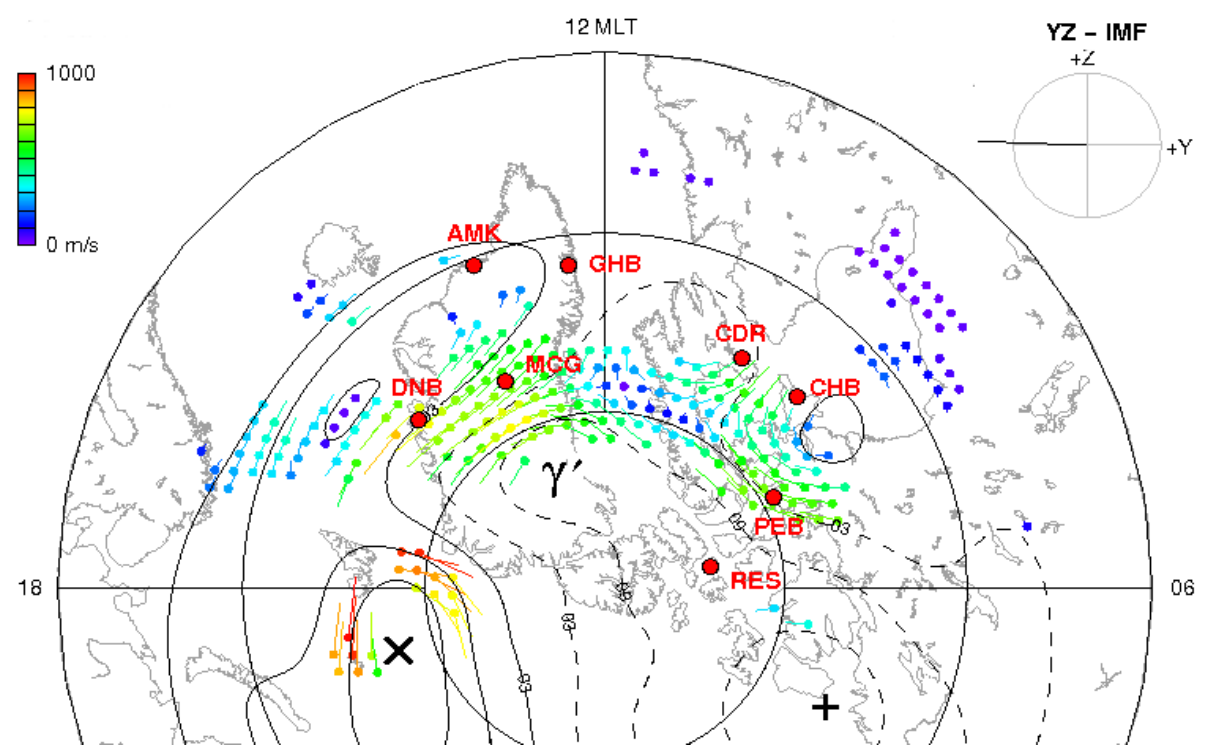

Fig. 6. Continued. Northern Hemisphere SuperDARN convection maps for 6 January 1998, between 14:18 and 14:22 UT. In panel (c), the field of view of Kapuskasing is also shown: the thick blue line evidence the direction of beam 11, the blue circle represents the region where the beam is supposed to cross the merging line footprint (see text), and the blue dotted curve represents a tentative merging line footprint.

a series of magnetic transients is observed in the morning around $75^{\circ}$ MLAT starting from 14:24 UT, up to 14:40 UT, whose features should make them fall into the class of TCVs (Zesta et al., 2002): a train of vortices is moving tailward with a speed of about $7-8 \mathrm{~km} / \mathrm{s}$. We suggest that the TCV-like features observed in the ionosphere correlate to the minor dynamic pressure variations which follow the SI. As regards the SuperDARN data, we do not observe any clear signature which can be related to such transients. This is probably due to two concurrent causes: the fact that their evolution occurs on a time scale comparable to the time resolution of a Super-
DARN scan, and the fact that their strongest effects probably develop at the southernmost edge of the radar coverage or even below.

\subsection{Enhanced lobe reconnection at the SI}

As we saw in Sect. 2.3 the SuperDARN convection maps show that the Northern Hemisphere convection patterns displayed a clear evolution in relation with the interacion of the SI with the magnetosphere. The description which we made of this evolution suggests that a prominent role is played by 


\section{(e) 14:22 - 14:24 UT}

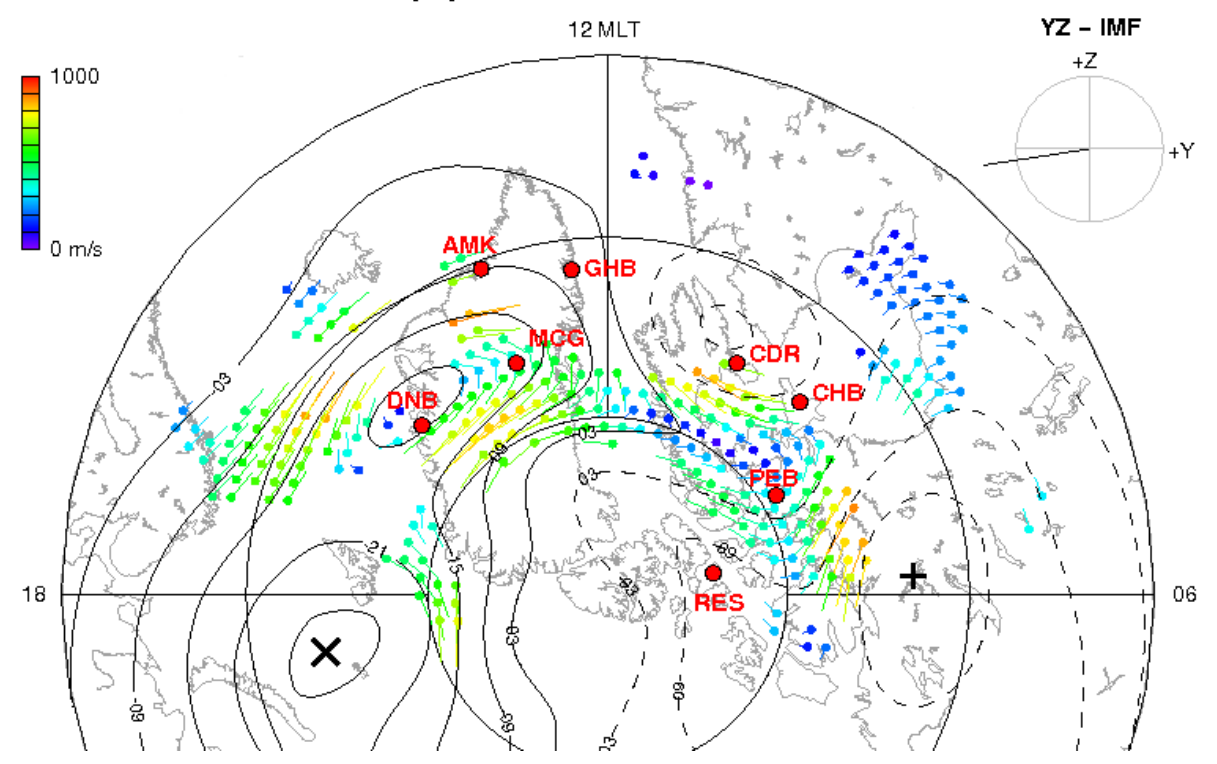

(f) 14:28 - 14:30 UT

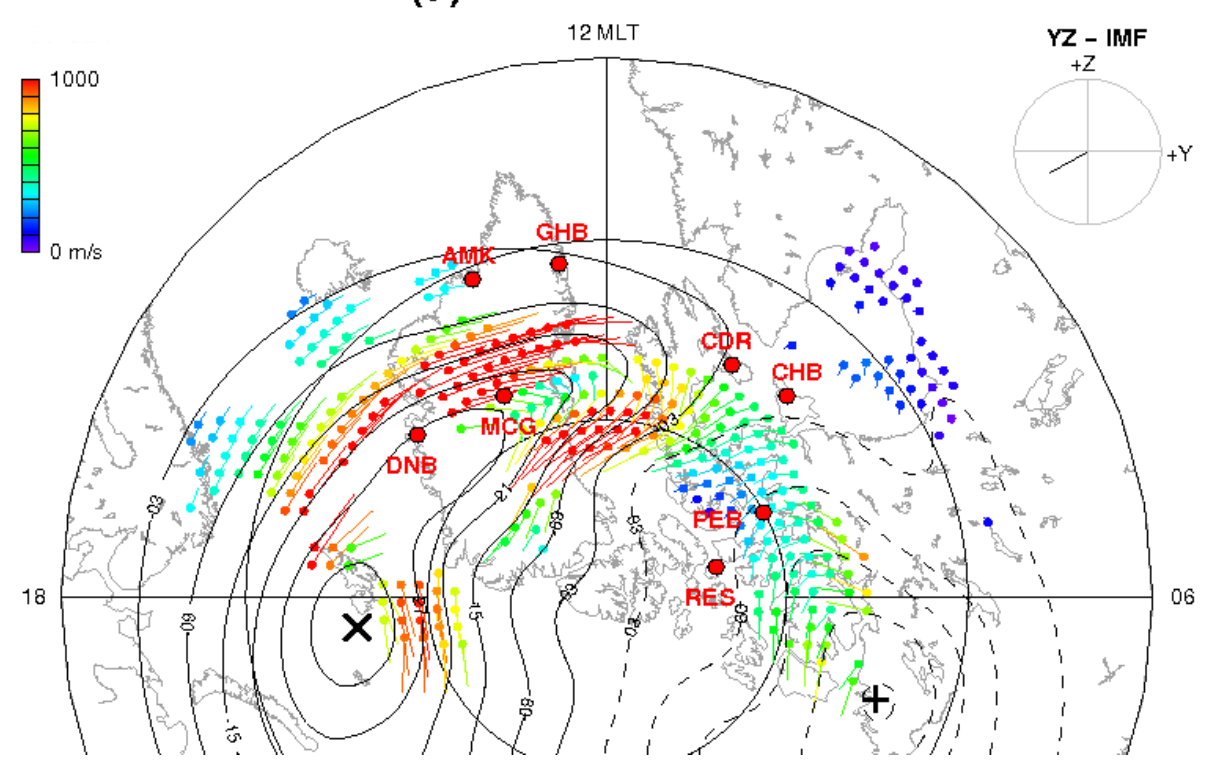

Fig. 6. Continued. Northern Hemisphere SuperDARN convection maps for 6 January 1998, between 14:22 and 14:30 UT.

the IMF orientation. Before we discuss more closely such an evolution and try to assess the possible complementary role of the solar wind dynamic pressure change, it is useful to briefly recall the expected configuration of the dayside convection when the IMF is $B_{y}$-dominated.

Figure 7 shows a scheme of the ionospheric patterns when $B_{y}<0$ (adapted from Sandholt et al., 1998). Figure 7a illustrates the expected convection pattern for $B_{z} \sim 0$ and $B_{y}<0$ : the two thick dashed lines show the projections of two reconnection lines, tailward and sunward of the Cusp respectively, which result in two cells, marked with $\alpha$ and $\beta$. Figure 7b refers to a configuration where $B_{z}>0$ : two stirring cells $\left(\gamma^{\prime}\right.$ and $\left.\delta^{\prime}\right)$ are formed due to an X-line tailward of the Cusp, resulting in a sunward flow from the polar cap, while two viscous cells ( $\alpha^{\prime}$ and $\beta^{\prime}$, clockwise at dusk and counterclockwise at dawn) convect field lines from the nightside at lower latitudes. When $B_{z}$ becomes negative, the expected convection pattern is the one shown in Fig. 7c: the X-line at the magnetopause forms at lower latitude, displaced along the dawn flank because of the negative $B_{y}$, and two asymmetric convection cells are expected to form in the high-latitude ionosphere.

Turning now to the real convection maps which we described in Sect. 2.3, we recall that both at the beginning and 
at the end of the period under study two convection cells were observed: clockwise at dusk and counterclockwise at dawn (Figs. 6a and f). This means that in both cases reconnection sunward of the cusp (i.e. at low latitude on the magnetopause) dominated and drove the high-latitude ionospheric convection. Further to that, in the first case one would expect a close similarity with the Fig. 7a scheme which cannot be further detailed, as the dawn cell extends only moderately to the dusk side and the paucity of data does not allow to unambiguously determine the lobe merging line. However, the patterns of Figs. 6a and $\mathrm{f}$ are clearly different: in the first case the convection is rather weak with a cross polar cap potential of $36 \mathrm{kV}$; in the second case the convection is much stronger and the two cells are neatly formed, with a dominating dusk cell and an estimated cross polar cap potential of $60 \mathrm{kV}$. Therefore, it is clear that the Fig. 6a pattern matches the $B_{z} \sim 0, B_{y}<0$ IMF orientation and that through the event the convection evolves to the Fig. $6 f$ pattern which closely resembles the Fig. 7c scheme, as expected from the new IMF orientation.

This is not unexpected. Conversely, the way in which this evolution occurs is to some extent surprising. In fact, the evolution of the IMF orientation as shown in Fig. 1 suggests that the IMF $B_{y}<0$ component should dominate reconnection at the magnetopause throughout the event. For a steadily dominant $B_{y}$ one would not expect the Fig. 6a pattern to vary much, exception made for a probable strengthening of convection induced by a more efficient reconnection process on the dawn side of the low latitude magnetopause. A different scenario emerges instead, as the convection maps in Fig. 6b$\mathrm{c}$, and d show: an intense sunward convection is activated in the morning, suggesting the emergence of a three-cell pattern (the new cells are labelled $\beta^{\prime}, \gamma^{\prime}$ and $\delta^{\prime}$ in Fig. $6 \mathrm{~b}-\mathrm{c}$ ). This pattern recalls the scheme sketched in Fig. $7 \mathrm{~b}$, which refers to a configuration where the contribution of $B_{z}>0$ is more important. This configuration shows up at its best in Fig. 6c, though for the $\alpha^{\prime}$ cell no direct observation is available. This pattern is still present in Fig. 6d, when at 14:20 UT $B_{z}$ turns negative and the convection pattern starts to evolve towards the Fig. 7c scheme, which is fully established several minutes later (Fig. 6f).

Also the MACCS magnetometers in the morning at very high latitudes (RES and PEB, Fig. 4), show evidence of the sunward convection seen in the SuperDARN maps: the $Y$ (East-West) component observes a decrease starting around 14:16 UT, reaches a minimum around 14:18, then rises again attaining a level higher than before the SI arrival (Fig. 4, right side); this is the effect of the increase of the Hall current from South to North, which is associated with the activation of the sunward convection fluxes. Furthermore, as little activity occurs in the East-West direction, the $X$ component does not register strong variations (Fig. 4, left side). On the other hand, in Northern Greenland, DNB and MCG stations observe a bay of the $H$-component which can be interpreted as the activation of a westward Hall current, or an eastward con- (a) IMF B $\mathrm{B}_{\mathrm{z}} \sim 0, \mathrm{~B}_{\mathrm{y}}<0$

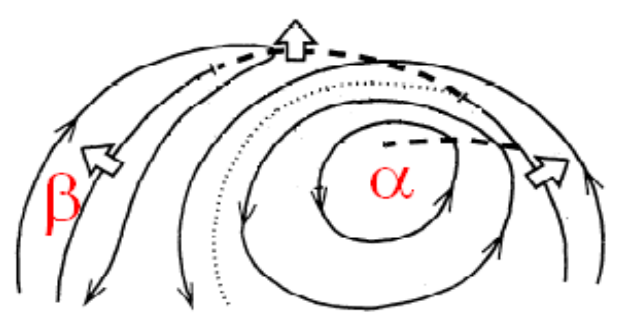

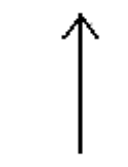

(b) IMF B $B_{z}>0, B_{y}<0$

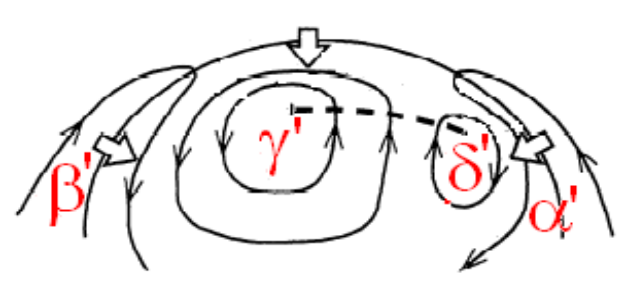

To Sun

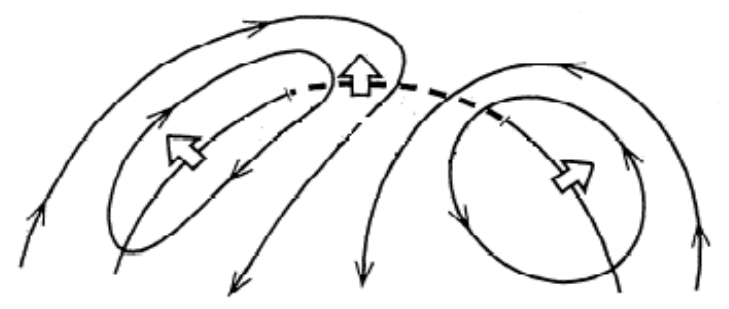

Fig. 7. High-latitude ionospheric convection pattern scheme expected when IMF $B_{y}<0$. From top to bottom the cases $B_{z} \sim 0$ (a), $B_{z}>0$ (b), $B_{z}<0$ (c) are displayed. Adapted from Sandholt et al. (1998).

vection flux, that is actually observed in that area (postnoon side of the $\gamma^{\prime}$ cell).

At this point it is worth recalling that the SuperDARN spectral width is a useful tool for distinguishing ionospheric regions where open or closed field lines map, especially in the cusp region and in the nightside. In fact, a number of studies has shown that, for southward IMF $B_{z}$, a sharp boundary can be traced between low and high spectral width values, which very often corresponds to the OCB and, therefore, to the dayside merging line footprint in the ionosphere (e.g. Milan et al., 1999; Moen et al., 2001; Chisham et al., 2008 , and references therein). On many occasions, the equatorward edge of the high spectral width region also marks the equatorward edge of the observed backscatter. Moreover Chisham et al. (2004) have shown that, when $B_{z}$ is northward, the poleward edge of the radar backscatter is often well correlated with the lobe merging line footprint in the 


\section{SuperDARN Spectral Widths 1998, January 6}

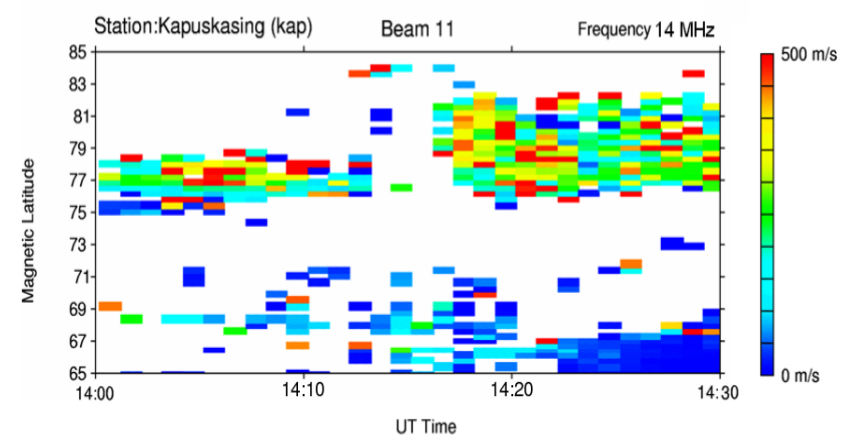

Fig. 8. SuperDARN spectral widths measured as a function of magnetic latitude between 14:00 and 14:30 UT for beam 11 of Kapuskasing radar.

ionosphere, while the OCB cannot be univocally identified with the low latitude edge of the radar backscatter. Figure 8 shows, as a function of magnetic latitude and UT, the spectral width measured by the Kapuskasing radar along its beam 11, which results to be quasi-meridionally oriented. The Kapuskasing field of view is delimited by red lines in Fig. 6c, and the direction of the selected beam is evidenced with a blue solid line. From Fig. 8 we can see that a latitudinal gap in the backscatter occurs between $71^{\circ}$ and $75^{\circ}$ MLAT, so delimiting an equatorward edge for the Cusp backscatter at about $75^{\circ}-76^{\circ}$ MLAT. However, such limit cannot be identified as the OCB as $B_{z}$ is northward until 14:22 UT. Actually, Figs. $6 \mathrm{~b}-\mathrm{d}$ show a sunward flow across such edge; if that edge were identified with the OCB, this would imply a concurrent movement of the OCB itself, to be explained through dual lobe reconnection. However, this is very unlikely to occur in this case, as $\left|B_{y}\right| \gg B_{z}>0$. Thus, it is reasonable to assume that the OCB be located somewhat more equatorward, i.e. along the dashed equipotential contour drawn in Fig. 6c at $72^{\circ}-73^{\circ}$ MLAT between 10:00 and 12:00 MLT. As for the poleward edge of the backscatter, one can notice a steep latitudinal transition: up to 14:16 UT the poleward edge was at $\sim 79^{\circ}$ MLAT, while from 14:22 UT, after a gap in the echoes, that boundary moves to $\sim 83^{\circ}$ MLAT. From these observations two main conclusions can be drawn: 1) the sunward fluxes described in Fig. $6 b-c$ lie on open field lines; 2) reconnection tailward of the cusp is possibly ongoing, with the merging line footprint located between $82^{\circ}$ and $83^{\circ}$ MLAT along the beam 11 direction. In Fig. $6 \mathrm{c}$ a blue circle has been overplotted along the beam 11 direction to indicate the region where the merging line footprint is supposed to cross the beam; a tentative merging line footprint can be traced from the centre of the reverse cell $\gamma^{\prime}$, through the circle, towards the reverse cell $\delta^{\prime}$, as indicated by the dashed blue curve in Fig. 6c.
To conclude this section, it is necessary to further comment on the possible cause of the enhanced lobe reconnection observed by SuperDARN between 14:16 and 14:22 UT. Therefore, we look more closely at the IMP-8 IMF change at the SI. Overall, although all three IMF components change, the rotation across the SI results to be $<3^{\circ}$. In particular, we notice that a small positive excursion of $B_{z}$, to a maximum value of $2 \mathrm{nT}$, is observed immediately after the SI; however, the small $B_{z}$ increase is accompanied by a large increase of the absolute value of $B_{y}$, so that, both before and after the IMF rotation, $\left|<B_{z}>\right| /\left|<B_{y}>\right| \simeq 0.1$, where the averages are calculated over $4 \mathrm{~min}$. In the second place, we examine the $B_{x}$ component, because some authors (e.g. Cowley, 1983; Crooker and Rich, 1993; Lockwood and Moen, $1999)$ suggested in the past that a negative $B_{x}$ can favor reconnection tailward of the northern cusp for $B_{z} \simeq 0$. For the event under study, the change of $B_{x}$ across the SI is of the same order as that of $B_{z}$ : before the SI, $B_{x} \simeq-0.6 \mathrm{nT}$, while immediately after it $B_{x} \simeq-2 \mathrm{nT}$, yielding a roughly constant ratio $\left|<B_{x}>\right| /\left|<B_{y}>\right| \simeq 0.1$. From these considerations we would not expect the conditions for reconnection at the magnetopause to change dramatically as a consequence of the IMF change associated with the SI.

To further evaluate this issue, we applied the Cooling et al. (2001) model of magnetopause reconnection using as inputs time shifted IMP-8 IMF data and WIND plasma data, respectively, before and after the SI. The Cooling et al. (2001) model allows to evaluate the probability of component merging as a function of position on the magnetopause and allows the reconstruction of an X-line on the magnetopause starting from a location where reconnection is considered to be feasable. For that purpose Cooling et al. (2001) make use of a model magnetopause and propagate the IMF and plasma data through the magnetosheath by using the Spreiter et al. (1966) gas-dynamic model. As such, the use of the Cooling model for this event somewhat compensates the lack of local magnetic and plasma measurements in the magnetosheath close to the magnetopause. We made runs of the Cooling model for the pre- and post-SI conditions and projected the obtained $\mathrm{X}$-lines to the ionosphere by using the Tsyganenko 96 model (Tsyganenko, 1995). We found that, as a consequence of the increase of IMF intensity across the SI, the Cooling model predicts an increased probability of reconnection, which qualitatively agrees with the increased convection observed by SuperDARN after the SI; however, as regards the topology of reconnection, the model predicts that an X-line sunward and eastward of the northern cusp can form, due to the large $B_{y}$ negative component, while we found no evidence for the formation of a merging line northward of the cusp like the one shown in Fig. 6c.

On the basis of the considerations we have just made, we suggest that the IMF change at the SI cannot explain by itself the sunward convection fluxes observed over the polar cap between 14:16 and 14:22 UT. As we are dealing with an SI, at this point it is natural to recall that several authors have 
proposed that pressure variations could favour reconnection or increase the reconnection rate (e.g. Prikryl et al., 1998; Provan et al., 2005). In particular, Bosqued et al. (2005) reported about CLUSTER observations of transient reconnection signatures in the Cusp region, which are often one to one correlated with repeated pressure variations, during a strongly $B_{y}$ dominated period. Further to that, Boudouridis et al. (2007) clearly showed that, for $B_{z}<0$, the pressure variations are often directly related to variations of the dayside reconnection rate. Finally, we recall that Laitinen et al. (2007) suggest that higher values of solar wind dynamic pressure yield increased reconnection rates at the magnetopause for $B_{z}<0$ and that the dominant parameter to account for such increased rates is solar wind velocity rather than density.

We therefore propose that for the event under study the solar wind dynamic pressure associated with the SI plays a role in favouring reconnection at the magnetopause. To this regard, we notice that, in this case, the density provides a large contribtion to the pressure increase as, at the $\mathrm{SI}, \Delta n \simeq 12 \mathrm{pp} / \mathrm{cm}^{3}$ and $\Delta V \simeq 80 \mathrm{~km} / \mathrm{s}$. Moreover, we remark a new result, consisting in the fact that the pressure increase triggers a clear lobe reconnection tailward of the northern Cusp and that a typical $B_{z}>0$ configuration is set up although $B_{y}<0$ dominates (Fig. $7 \mathrm{~b}$ ). We suggest that the setting up of lobe reconnection under the influence of increased solar wind dynamic pressure might be linked to the indentation of the magnetosheath flow in the cups region. To this regard, one could speculate that the orientation of the solar wind shock in this case (Sect. 3.1) might also play a role in producing an asymmetric deformation of the magnetopause surface. However, such considerations cannot be supported by detailed evidence in this case and further work is needed in identifying similar events and developing adequate modelling.

\section{Summary and conclusions}

We have used SuperDARN convection maps, spacecraft data and ground magnetometer data to study the effect of a Sudden Impulse (SI) of solar wind dynamic pressure on the magnetosphere-ionosphere system. We have found that the shock front associated with the SI was tilted towards the dawn flank of the magnetopause, and occurred during an IMF $B_{y}$-dominated period, with $B_{z}>0$. Regarding the general effects of the SI, we have shown that current systems are established in the magnetosphere and in the high-latitude ionosphere that can be clearly related to a "pure" SI effect. In fact, satellites in the equatorial plane of the magnetosphere and equatorial ground-based magnetometers report an increase of the geomagnetic field which is caused by an increase of the Chapman-Ferraro current from dawn to dusk: this is the effect of the magnetospheric compression and of the MHD wave started from the first impact point of the SI on the magnetopause. On the other hand, ground-based magnetome- ters at high-latitudes observe convection vortices which can be related to FAC systems coming from the inner magnetosphere, with signatures showing a general agreement with the Araki model of the SIs (Araki, 1994). Further to that, we have found a new result which can be summarised as follows:

1. at very high latitudes in the Cusp and in the morning sector, intense sunward convection fluxes appear, well correlated in time with the SI arrival;

2. these fluxes last for 5-6 min, until the rotation of IMF $B_{z}$ to negative values leads to a global reconfiguration of the high-latitude convection to a typical two-cell $B_{y}<0$ pattern;

3. these fluxes have a signature typical for $B_{z}>0$ dominated lobe reconnection, while $\left|B_{y}\right| \gg B_{z}$, and seem to be triggered by the solar wind dynamic pressure increase.

Acknowledgements. The authors would like to thank: R. Lepping and K. Ogilvie for the use of WIND magnetic field and solar wind experiments data, respectively; N. Ness for the use of ACE Magnetic Field Instrument data; A. Szabo and R. Lepping for the use of IMP-8 Magnetic Field Instrument data; S. Kokubun for the use of GEOTAIL Magnetic Field Instrument data; the CDAWeb team; the World Data Center for Geomagnetism, Kyoto, Japan, for providing low-latitude magnetograms; M. Engebretson and W. J. Hughes for the use of MACCS magnetometers data; J. Watermann for the use of DMI Greenland magnetometers data; R. Clauer for the use of MAGIC magnetometers data. We would also like to thank all of the Principal Investigators of the SuperDARN radars.

Special thanks go to Jean-Claude Cerisier at CETP, France, and to Jean-Pièrre St. Maurice, at the University of Saskatchewan, Canada, for the useful and stimulating discussions at the early stages of that work. This work is supported by the Italian National Program for Antarctic Research (PNRA), under projects 2004/7.1 and 2004/7.2.

Topical Editor I. A. Daglis thanks two anonymous referees for their help in evaluating this paper.

\section{References}

Araki, T.: A physical model of the geomagnetic sudden commencement, in: Solar Wind Sources of Magnetospheric Ultra-LowFrequency Waves, Geophys. Monogr. Ser., 81, 183-200, 1994.

Baker, K. B., Dudeney, J. R., Greenwald, R. A., Pinnock, M., Newell, P. T., Rodger, A. S., Mattin, N., and Meng, C.-I.: HF radar signatures of the cusp and low-latitude boundary layer, J. Geophys. Res., 100, 7671-7695, 1995.

Bosqued, J. M., Escoubet, C. P., Frey, H. U., Dunlop, M., Berchem, J., Marchaudon, A., Cerisier, J. C., Fazakerley, A., Budnik, E., Lavraud, B., Rème, H., Laakso, H., and Balogh, A.: Multipoint observations of transient reconnection signatures in the cusp precipitation: A Cluster-IMAGE detailed case study, J. Geophys. Res., 110, A03219, doi:10.1029/2004JA010621, 2005.

Boudouridis, A., Zesta, E., Lyons, L. R., Anderson, P. C., and Lummerzheim, D.: Effect of solar wind pressure pulses on the size and strength of the auroral oval, J. Geophys. Res., 108(A4), 8012, doi:10.1029/2002JA009373, 2003. 
Boudouridis, A., Lyons, L. R., Zesta, E., and Ruohoniemi, J. M.: Dayside reconnection enhancement resulting from a solar wind dynamic pressure increase, J. Geophys. Res., 112, A06201, doi:10.1029/2006JA012141, 2007.

Burke, W. J., Kelley, M. C., Sagalyn, R. C., Smiddy, M., and Lai, S. T.: Polar cap electric field structures with a northward interplanetary magnetic field, Geophys. Res. Lett., 6, 21-24, 1979.

Chisham, G., Freeman, M. P., Coleman, I. J., Pinnock, M., Hairston, M. R., Lester, M., and Sofko, G.: Measuring the dayside reconnection rate during an interval of due northward interplanetary magnetic field, Ann. Geophys., 22, 4243-4258, 2004, http://www.ann-geophys.net/22/4243/2004/.

Chisham, G., Lester, M., Milan, S. E., Freeman, M. P., Bristow, W. A., Grocott, A., McWilliams, K. A., Ruohoniemi, J. M., Yeoman, T. K., Dyson, P. L., Greenwald, R. A., Kikuchi, T., Pinnock, M., Rash, J. P. S., Sato, N., Sofko, G. J., Villain, J.-P., and Walker, A. D. M.: A decade of the Super Dual Auroral Radar Network (SuperDARN): scientific achievements, new techniques and future directions, Surv. Geophys., 28, 33-109, 2007.

Chisham, G., Freeman, M. P., Abel, G. A., Lam, M. M., Pinnock, M., Coleman, I. J., Milan, S. E., Lester, M., Bristow, W. A., Greenwald, R. A., Sofko, G. J., and Villain, J.-P.: Remote sensing of the spatial and temporal structure of magnetopause and magnetotail reconnection from the ionosphere, Rev. Geophys., 46, RG1004, doi:10.1029/2007RG000223, 2008.

Coco, I., Amata, E., Marcucci, M. F., De Laurentis, M., Villain, J.-P., Hanuise, C., and Candidi, M.: Effects on SuperDARN HF radar echoes of sudden impulses of solar wind dynamic pressure, Ann. Geophys., 23, 1771-1783, 2005,

http://www.ann-geophys.net/23/1771/2005/.

Cooling, B. M. A., Owen, C. J., and Schwartz, S. J.: Role of the magnetosheath flow in determining the motion of open flux tubes, J. Geophys. Res., 106, 18 763-18 776, 2001.

Cowley, S. W. H.: Interpretation of observed relations between solar-wind characteristics and effects at ionospheric altitudes, in: High Latitude Space Plasma Physics, edited by: Hultqvist, B. and Hagfors, T., 225-249, Plenum, New York, 1983.

Crooker, N. U.: Dayside Merging and Cusp Geometry, J. Geophys. Res., 84, 951-959, 1979.

Crooker, N. U. and Rich, F. J.: Lobe cell convection as a summer phenomenon, J. Geophys. Res., 98, 13 403-13 407, 1993.

Dungey, J. W.: Interplanetary magnetic field and the auroral zones, Phys. Rev. Lett., 6, 47-50, 1961.

Erlandson, R. E., Sibeck, D. G., Lopez, R. E., Zanetti, L. J., and Potemra, T. A.: Observations of solar wind pressure initiated fast mode waves at geostationary orbit and in the polar cap, J. Atmos. Terr. Phys., 53, 231-239, 1991.

Francia, P., Lepidi, S., Villante, U., Di Giuseppe, P., and Lazarus, A. J.: Geomagnetic response at low latitude to continuous solar wind pressure variations during northward interplanetary magnetic field, J. Geophys. Res., 104, 19923-19930, 1999.

Glassmeier, K.-H., Hönisch, M., and Untiedt, J.: Ground-Based and Satellite Observations of Traveling Convection Twin Vortices, J. Geophys. Res., 94, 2520-2528, 1989.

Gosling, J. T., Thomsen, M. F., Bame, S. J., Elphic, R. C., and Russell, C. T.: Plasma flow reversals at the dayside magnetopause and the origin of asymmetric polar cap convection, J. Geophys. Res., 95, 8073-8084, 1990.

Greenwald, R. A., Baker, K. B., Dudeney, J. R., Pinnock, M., Jones,
T. B., Thomas, E. C., Villain, J.-P., Cerisier, J.-C., Senior, C., Hanuise, C., Hunsucker, R. D., Sofko, G., Koehler, J., Nielsen, E., Pellinen, R., Walker, A. D. M., Sato, N., and Yamagishi, H.: DARN/SUPERDARN: A Global View of the Dynamics of HighLatitude Convection, Space Sci. Rev., 71, 761-796, 1995.

Hanuise, C., Greenwald, R. A., and Baker, K. B.: Drift motions of very high latitude $\mathrm{F}$ region irregularities: Azimuthal Doppler analysis, J. Geophys. Res., 90, 9717-9725, 1985.

Hanuise, C., Villain, J.-P., Gresillon, D., Cabrit, B., Greenwald, R. A., and Baker, K. B.: Interpretation of HF radar ionospheric Doppler spectra by collective wave scattering theory, Ann. Geophys., 11, 29-39, 1993, http://www.ann-geophys.net/11/29/1993/.

Huang, C.-S., Andre, D. A., Sofko, G. J., and Koustov, A. V.: Super Dual Auroral Radar Network observations of ionospheric multicell convection during northward interplanetary magnetic field, J. Geophys. Res., 105, 7419-7428, 2000.

Kivelson, M. G. and Southwood, D. J.: Ionospheric Traveling Vortex Generation by Solar Wind Buffeting on the Magnetopause, J. Geophys. Res., 96, 1661-1667, 1991.

Kozlovsky, A., Safargaleev, V., Østgaard, N., Turunen, T., Koustov, A., Jussila, J., and Roldugin, A.: On the motion of dayside auroras caused by a solar wind pressure pulse, Ann. Geophys., 23, 509-521, 2005, http://www.ann-geophys.net/23/509/2005/.

Laitinen, T. V., Palmroth, M., Pulkkinen, T. I., Janhunen, P., and Koskinen, H. E. J.: Continuous reconnection line and pressure-dependent energy conversion on the magnetopause in a global MHD model, J. Geophys. Res., 112, A11201, doi:10.1029/2007JA012352, 2007.

Lockwood, M. and Moen, J.: Reconfiguration and closure of lobe flux by reconnection during northward IMF: Evidence for signatures in cusp/cleft auroral emissions, Ann. Geophys., 17, 9961011, 1999, http://www.ann-geophys.net/17/996/1999/.

Milan, S. E., Cowley, S. W. H., Moen, J., Sandholt, P. E., and Owen, C. J.: Meridian scanning photometer, coherent HF radar, and magnetometer observations of the cusp: a case study, Ann. Geophys., 17, 159-172, 1999,

http://www.ann-geophys.net/17/159/1999/.

Moen, J., Carlson, H. C., Milan, S. E., Shumilov, N., Lybekk, B., Sandholt, P. E., and Lester, M.: On the collocation between dayside auroral activity and coherent HF backscatter, Ann. Geophys., 18, 1531-1549, 2001, http://www.ann-geophys.net/18/1531/2001/.

Motoba, T., Kikuchi, T., Okuzawa, T., and Yumoto, K.: Dynamical response of the magnetosphere-ionosphere system to a solar wind dynamic pressure oscillation, J. Geophys. Res., 108(A5), 1206, doi:10.1029/2002JA009696, 2003.

Newell, P. T. and Meng, C.-I.: Ionospheric projection of magnetospheric regions under low and high solar wind pressure conditions, J. Geophys. Res., 99, 273-286, 1994.

Prikryl, P., Greenwald, R. A., Sofko, G. J., Villain, J.-P., Ziesolleck, C. W. S., and Friis-Christensen, E.: Solar-wind-driven pulsed magnetic reconnection at the dayside magnetopause, Pc5 compressional oscillations, and field line resonances, J. Geophys. Res., 103, 17 307-17 322, 1998.

Provan, G., Lester, M., Cowley, S. W. H., Milan, S. E., Hubert, B., and Khan, H.: Modulation of dayside reconnection during northward interplanetary magnetic field, J. Geophys. Res., 110, A10211, doi:10.1029/2004JA010980, 2005. 
Reiff, P. H. and Burch, J. L.: IMF $B_{y}$-dependent plasma flow and Birkeland currents in the dayside magnetosphere 2. A global model for northward and southward IMF, J. Geophys. Res., 90, 1595-1609, 1985.

Ruohoniemi, J. M. and Baker, K. B.: Large-scale imaging of highlatitude convection with Super Dual Auroral Radar Network HF radars observations, J. Geophys. Res., 103, 20 797-20 811, 1998.

Ruohoniemi, J. M. and Greenwald, R. A.: Statistical patterns of high-latitude convection obtained from Goose Bay HF radar observations, J. Geophys. Res., 101, 21 743-21 763, 1996.

Ruohoniemi, J. M. and Greenwald, R. A.: Dependencies of high-latitude plasma convection: Consideration of interplanetary magnetic field, seasonal, and universal time factors in statistical patterns, J. Geophys. Res., 110, A09204, doi:10.1029/2004JA010815, 2005.

Russell, C. T. and Ginskey, M.: Sudden impulses at subauroral latitudes: Response for northward interplanetary magnetic field, J. Geophys. Res., 100, 23 695-23 702, 1995.

Sandholt, P. E., Farrugia, C. J., Moen, J., and Cowley, S. W. H.: Dayside auroral configuration: Response to southward and northward rotations of the interplanetary magnetic field, J. Geophys. Res., 103, 20 279-20 295, 1998.

Schwartz, S. J.: Shock and discontinuity normals, Mach numbers, and related parameters, in: Analysis Methods for MultiSpacecraft Data, edited by: Paschmann, G. and Daly, P. W., ISSI editions, Chap. 10, 1998.

Sibeck, D. G.: A Model for the Transient Magnetospheric Response to Sudden Solar Wind Dynamic Pressure Variations, J. Geophys. Res., 95, 3755-3771, 1990.

Sibeck, D. G., Trivedi, N. B., Zesta, E., Decker, R. B., Singer, H. J., Szabo, A., Tachihara, H., and Watermann, J.: Pressure-pulse interaction with the magnetosphere and the ionosphere, J. Geophys. Res., 108(A2), 1095, doi:10.1029/2002JA009675, 2003.
Southwood, D. J. and Kivelson, M. G.: The Magnetohydrodynamic Response of the Magnetospheric Cavity to Changes in Solar Wind Pressure, J. Geophys. Res., 95, 2301-2310, 1990.

Spreiter, J. R., Summers, A. L., and Alksne, A. Y.: Hydromagnetic flow around the magnetosphere., Planet. Space Sci., 14, 223 253, 1966.

Thorolfsson, A., Cerisier, J.-C., and Pinnock, M.: Flow transients in the postnoon ionosphere: The role of solar wind dynamic pressure, J. Geophys. Res., 106, 1887-1901, 2001.

Tsyganenko, N. A.: Modeling the Earth's magnetospheric magnetic field confined within a realistic magnetopause, J. Geophys. Res., 100, 5599-5612, 1995.

Villain, J.-P., Beghin, C., and Hanuise, C.: ARCAD3-SAFARI coordinated study of auroral and polar F-region ionospheric irregularities, Ann. Geophys., 4, 61-68, 1986, http://www.ann-geophys.net/4/61/1986/.

Vontrat-Reberac, A., Cerisier, J.-C., Sato, N., and Lester, M.: Noon ionospheric signatures of a sudden commencement following a solar wind pressure pulse, Ann. Geophys., 20, 639-645, 2002, http://www.ann-geophys.net/20/639/2002/.

Wang, C., Li, C. X., Huang, Z. H., and Richardson, J. D.: Effect of interplanetary shock strengths and orientations on storm sudden commencement rise time, Geophys. Res. Lett., 33, L14104, doi:10.1029/2006GL025966, 2006.

Wilken, B., Goertz, C. K., Baker, D. N., Higbie, P. R., and Fritz, T. A.: The SSC on July 29, 1977 and its Propagation Within the Magnetosphere, J. Geophys. Res., 87, 5901-5910, 1982.

Zesta, E., Hughes, W. J., and Engebretson, M. J.: A statistical study of traveling convection vortices using the Magnetometer Array for Cusp and Cleft Studies, J. Geophys. Res., 107, 1317, doi:10.1029/1999JA000386, 2002.

Zhou, X. and Tsurutani, B. T.: Rapid intensification and propagation of the dayside aurora: Large scale interplanetary pressure pulses (fast shocks), Geophys. Res. Lett., 26, 1097-1100, 1999. 